\title{
$\mathrm{R} C \& \mathrm{C}$
}

\section{AÇÕES DO CONSELHO FEDERAL DE CONTABILIDADE NO DESENVOLVIMENTO DA CONTABILIDADE BRASILEIRA}

\section{ACTIONS OF FEDERAL ACCOUNTING COUNCIL FOR DEVELOPMENT AND BRAZILIAN ACCOUNTING}

\author{
Recebido em 16.02.2013 | Aceite final em 20.07.2013 |
}

Nota: este artigo foi aceito pelo Editor Jorge Eduardo Scarpin e passou por uma avaliação double blind review A reprodução dos artigos, total ou parcial, pode ser feita desde que citada a fonte.

MARIA CLARA CAVALCANTE BUGARIM Doutora em Administração de Empresas | Universidade Federal de Santa Catarina | Diretora do Centro de Comunicação e Gestão | Universidade de Fortaleza | Av. Washington Soares, 1321 | CCA | Bloco R | Sala 04 | Engenheiro Luciano Cavalcante | Fortaleza-CE - Brasil | Telefone: (+5585) 9925-3333 | E-mail: mclara.bugarim@unifor.br |

\section{JOAQUIM CARLOS DA COSTA PINHO} Diretor do Programa Doutoral em Contabilidade | Universidade de Aveiro | Campus Universitário de Santiago | 3810-193 | Aveiro - Portugal | Telefone: (+351) 234-370-200| E-mail: cpinho@ua.pt |

\section{LÚCIA LIMA RODRIGUES}

Diretora do Mestrado em Contabilidade | Universidade do Minho | Escola de Economia e Gestão | Campus de Gualtar | Braga - Portugal | 4710-057 | Telefone: (+351) 253-604-559 | E-mail: Irodrigues@eeg.uminho.pt |

\section{DIEGO DE QUEIROZ MACHADO}

Doutorando do Programa de Pós-Graduação em Administração | Universidade de Fortaleza | Av. Washington Soares, 1321 | PPGA | Bloco Q | Sala 03| Engenheiro Luciano Cavalcante | Fortaleza-CE - Brasil | Telefone: (+5585) 9710-4170 | E-mail: diegoqueirozm@yahoo.com.br |

\section{RESUMO}

Em contraste ao considerável e reconhecido volume de trabalhos que objetivam analisar os diversos elementos presentes no desenvolvimento da Contabilidade no Brasil, reconhece-se uma grande lacuna nesses mesmos trabalhos ao desconsiderar a influência exercida pelo Conselho Federal de Contabilidade (CFC) e Conselhos Regionais de Contabilidade (CRCS) neste processo. Neste contexto, este estudo concentra seus esforços de investigação e análise no seguinte objetivo geral: apresentar as principais realizações do Sistema CFC/CRCs no desenvolvimento e evolução da 
Contabilidade brasileira. Para tanto, optou-se pela utilização de uma abordagem qualitativa, aplicada mediante pesquisa historiográfica clássica com o uso da análise documental. Os documentos utilizados foram, principalmente, os relatórios internos do próprio Conselho Federal de Contabilidade e de seus Conselhos Regionais, além de documentos de comunicação do CFC e CRCs, como jornais, revistas e boletins institucionais, que guardam acontecimentos marcantes dos quase setenta anos de história desta entidade. Inicialmente, a revisão bibliográfica que se concentrou na história da Contabilidade no Brasil evidenciou conquistas importantes nos primeiros séculos do país. Essa primeira fase histórica da Contabilidade no Brasil tem seu final em 1946, exatamente com a criação do Conselho Federal de Contabilidade. De fato, desde a sua criação, a atuação do Conselho Federal e Conselhos Regionais se mostra como fundamental para a evolução das práticas contábeis no país. Na pesquisa documental, ao serem ressaltados aspectos referentes à criação do código de ética profissional do contabilista, o processo de alteração na regulamentação da profissão e a criação da lei da representatividade, enfatiza-se a preocupação da entidade com a evolução das práticas contábeis no país, de forma a acompanhar as tendências internacionais do campo.

Palavras-chave: Contabilidade Brasileira. Conselho Federal de Contabilidade. Conselhos Regionais de Contabilidade. Pesquisa Historiográfica.

\begin{abstract}
In contrast to the considerable and recognized volume of works that aim to analyze the various elements present in the development of Accounting in Brazil, it is recognized a major gap in these papers to dismiss the influence of the Federal Accounting Council (CFC) and Regional Accounting Councils (CRCs) in this process. In this context, this study focuses its research efforts and analysis in the following general objective: to present the main achievements of the CFC/CRCs system in the development and evolution of the Brazilian Accounting. Therefore, we chose to use a qualitative approach, applied through historical research using the classic documentary analysis. The documents used were mainly internal reports of the Federal Accounting Council itself and its Regional Councils, and communication documents of CFC and CRCs, such as newspapers, magazines and newsletters institutional, that guarding key events of nearly seventy years of history this entity. Initially, the literature review that focused on the history of accounting in Brazil showed significant gains in the early centuries of the country. This first phase of historical accounting in Brazil has its end in 1946, just with the creation of the Federal Accounting Council. In fact, since its inception, the role of the Federal Council and Regional Councils shows as fundamental to the evolution of accounting practices in the country. In the documentary research to be highlighted issues relating to the creation of the code of professional ethics of the accounting, the process of change in the regulation of the profession of law and the creation of representativeness, emphasizes the concern of the entity with
\end{abstract}


the evolution of accounting practices in the country, in order to follow international trends in the field.

Keywords: Brazilian Accounting. Federal Accounting Council. Regional Accounting Councils. Historical Research.

\section{INTRODUÇÃO}

Dentro do campo das ciências sociais aplicadas, a Contabilidade têm expandido seus eixos de atuação ao longo dos últimos séculos de forma a responder aos mais diversos cenários de atuação das atividades humanas, seja no contexto econômico ou, mais recentemente, social. Para tanto, inúmeras ferramentas e mecanismos de auxílio às práticas contábeis foram desenvolvidos e disseminados junto aos governos, organizações e indivíduos, fazendo das ciências contábeis uma instituição em si mesma, fundamental para a sustentação de qualquer sociedade e evoluindo juntamente com esta última.

No decorrer dos últimos anos, inúmeros trabalhos têm surgido com o intuito de discorrer acerca do desenvolvimento das ciências contábeis, tanto em contextos mais gerais, como é o caso dos estudos de Martins (2001), Pereira (2006), Carnegie e Rodrigues (2007) e Buesa (2010), como focados em nações específicas, por exemplo: Pigatto e Lisboa (1999) na Alemanha; Rodrigues (2007) na China; Rodrigues e Gomes (2002) e Lira (2011) em Portugal; Niyama e Silva (2005), Sá (2008), Agrizzi e Sian (2010) e Sebold, Pioner, Schappo e Pioner (2012) no Brasil.

Contudo, uma característica comum e fortemente percebida nos trabalhos já desenvolvidos no campo, reside na ausência ou pouca preocupação em explorar relações históricas entre os fatos conhecidos da evolução das ciências contábeis e seu atual estágio de desenvolvimento. Além disso, a opção pela concentração dos estudos em elementos pontuais demanda uma apreciação que reúna os mais diversos aspectos referentes ao contexto das atividades e práticas contábeis, como as contribuições das legislações, o papel das instituições de ensino, o desenvolvimento de profissionais e a influência dos órgãos de fiscalização.

No Brasil, um agente que se destaca neste contexto como o principal responsável pela condução do sistema contábil é o Conselho Federal de Contabilidade (CFC), órgão criado em 1946, cujas linhas de ação se desenvolvem junto aos Conselhos Regionais de Contabilidade (CRCs), destinados a fiscalizar o exercício das profissões de contador (bacharel em ciências contábeis) e de técnico em Contabilidade. Para tanto, desde a sua criação, o CFC vêm buscando cumprir suas prerrogativas legais, desenvolvendo programas de fiscalização que visem proteger não apenas os contabilistas, o que caracterizaria uma visão corporativa, mas, acima de tudo, a sociedade, guardando-a de profissionais que não se encontrem preparados para atuar no mercado de trabalho.

Assim, em contraste ao considerável e reconhecido volume de trabalhos que objetivam analisar os diversos elementos presentes no desenvolvimento da Contabilidade no Brasil, reconhece-se uma grande lacuna nesses mesmos trabalhos ao desconsiderar a influência exercida pelo sistema CFC/CRCs e sua história neste processo. De fato, este é um aspecto que merece profunda apreciação, tendo em vista que as histórias da Contabilidade no Brasil e do sistema CFC/CRCs se inter-relacionam de tal maneira que chegam a se confundir em uma única história. O desafio, portanto, versa sobre a complexidade desta relação enquanto agentes distintos, mas cujos aspectos se misturam e se influenciam mutuamente.

Neste contexto e diante da ausência de pesquisas relativas à atuação do Sistema CFC/CRCs no desenvolvimento da Contabilidade no Brasil, este estudo concentra seus esforços de investigação e análise no seguinte objetivo geral: apresentar as principais realizações do Sistema CFC/CRCs no desenvolvimento e evolução da Contabilidade brasileira. Neste intuito, optou-se pela utilização de uma abordagem qualitativa, aplicada mediante pesquisa historiográfica clássica com o uso da análise 
documental. Os documentos utilizados foram, principalmente, os relatórios internos do próprio Conselho Federal de Contabilidade e de seus Conselhos Regionais, além de documentos de comunicação do CFC e CRCs, como jornais, revistas e boletins institucionais, que guardam acontecimentos marcantes dos quase setenta anos de história desta entidade.

Dessa forma, espera-se que este trabalho possa contribuir com as demais pesquisas realizadas no campo da história da Contabilidade brasileira, explorando a atuação do Sistema CFC/CRCs como agente promotor e regularizador de seu desenvolvimento.

\section{O DESENVOLVIMENTO DA CONTABILIDADE NO MUNDO}

O nascimento da Contabilidade ocorreu há milhares de anos juntamente com o surgimento do patrimônio e a necessidade de registrá-lo, como relata Toledo Filho (1980, p.1):

Sua origem e desenvolvimento foram fruto do trabalho coletivo, na medida em que as necessidades de registro e controle foram se tornando mais complexas. Assim, quando o homem primitivo aprendeu a armazenar seu alimento ou a trocar o produto de sua caça por utensílios, sentiu a necessidade de registrar esses fatos.

A Contabilidade está presente na história da humanidade desde povos mais antigos como os hindus, os chineses, os egípcios, os fenícios, os israelitas, os persas, os caldeus, os assírios, os gregos e os romanos, ganhando destaque com o surgimento da linguagem escrita dos números (SILVA E MARTINS, 2006).

Com a evolução das sociedades, também evolui a Contabilidade. A partir do século XIII d.C. novas técnicas contábeis foram surgindo, livros contábeis começaram a ser adotados para registrar os principais eventos econômicos das empresas e as obras do monge italiano Luca Pacioli, considerado pai da Contabilidade moderna, expuseram os métodos que impulsionaram o pensamento contábil, como o método das partidas dobradas (SCHMIDT, 1996).

A invenção da prensa, no século XV, fez com que os ensinamentos de Pacioli fossem difundidos para o mundo e proporcionou que outras obras de autores que ensinavam a teoria contábil fossem publicadas e divulgadas, como narra Lopes Sá (apud SILVA E MARTINS, 2006, p. 62) como sendo a era científica da Contabilidade:

O período científico foi aquele em que as doutrinas se agigantaram, determinadas não só em buscar a delimitação de um objeto verdadeiro de estudos para a Contabilidade, mas também, especialmente de buscar conhecer a sustância gerida pelo ser humano no sentido de satisfação de suas necessidades materiais.

Na Europa, a fundação da Aula do Comércio portuguesa em 1759, com sede em Lisboa, que foi a primeira escola oficial a oferecer instrução formal em comércio, com o ensino da Contabilidade e método das partidas dobradas se constituiu como um marco, ressaltam Rodrigues, Gomes e Graig (2004, 2007). Sua importância reside na interveção do governo no seu financiamento já que, anteriormente, apenas em escolas privadas eram encontrados cursos para a área de comércio e Contabilidade. Sua criação, portanto, aponta para um início de preocupação da gestão pública com a área das ciências contábeis.

No século XIX, a Contabilidade já era vista como uma ciência e vários fatores alavancaram seu desenvolvimento e reconhecimento, dentre outros (TOLEDO FILHO, 1980):

a) A regulamentação, em 1805, pelo imperador da França, Napoleão I, da profissão de contador;

b) A disciplina de Contabilidade passou a ser ministrada nas Universidades de Viena, Pádua e Praga; 
c) Francesco Villa publica La Contabilitá Applicata alle Amministrazioni Private e Publiche, considerada pelos autores italianos como o marco que afirma a Contabilidade como ciência;

d) A fundação da Société Académique de Comptabilité na França com o objetivo de propagar o ensino comecial e aperfeiçoar a Contabilidade;

e) A publicação de La Ragioneria Scientifica por Giuseppe Cerboni, onde, segundo ele, "a Contabilidade é a ciência da administração econômico-administrativa".

O progresso que estava acontecendo na Contabilidade demandou, principalmente após o crack da bolsa em 1929, uma fixação de padrões contábeis e sua regulamentação, crescendo também a importância da auditoria. Posteriormente, com o fim da II Guerra Mundial, com a liberação da demanda reprimida de bens e serviços, as informações contábeis tornam-se imprescindíveis para os investidores, auxiliando-os na análise da situação financeira das empresas (BACCl, 2002).

$\mathrm{Na}$ atualidade, a profissão contábil possui uma dimensão bem mais ampla, como comenta D'Áuria (apud SILVA E MARTINS, 2006, p.57): “O contador de hoje não é um simples registrador de operações comerciais. Sua função desdobrou-se nas mesmas proporções da Contabilidade, desempenhando o papel de consulto, jurídico-comercial, economia, administração matemática e estatística".

\section{A HISTÓRIA DA CONTABILIDADE BRASILEIRA}

A história da Contabilidade no Brasil começa lentamente seguindo o ritmo das primeiras sociedades civilizadas brasileiras fundadas pelos portugueses alguns anos após o descobrimento. Em 1551, foi designado o primeiro contador, o Rei D. João III nomeia Brás Cubas para o cargo de Provedor da Fazenda Real e Contador das Rendas e Direitos da Capitania e em 1561 foi criado o Conselho de Fazenda para a administração financeira das colônias (RODRIGUES, 1985).

Segundo Watanabe (1996), a origem da formação profissional do contador no Brasil ocorreu em 1754 por proposta do governador do Estado de Grão Pará e Maranhão, Francisco Xavier de Mendonça Furtado, irmão do futuro marquês de Pombal. Ainda em 1754, foi proposta partida do Brasil a criação de uma Aula de Comércio (na época, o termo "aula" referia-se a um ensino superior ou faculdade), sob a supervisão da Junta de Comércio de Lisboa, sendo a proposta aprovada pelo decreto de 12 de dezembro de 1756.

Após a chegada da família real no Brasil, em 1808, D. João VI criou a Real Junta de Comércio, Agricultura, Fábricas e Navegação e, com o objetivo de controlar seus bens, determinou a adoção do sistema de paridas dobradas pelo seu reconhecimento nos países da Europa (BACCI, 2002).

De acordo com Schmidt (1996), a Contabilidade brasileira sempre sofreu uma ampla influência da legislação. Uma das primeiras grandes manifestações da legislação no cenário brasileiro foi o Código Comercial de 1850 que instituiu a obrigatoriedade da escrituração contábil e da elaboração anual da demonstração do Balanço Geral.

Teles (1989) enfatiza a importância do Código Comercial brasileiro ressaltando que, após 350 anos do descobrimento, o Brasil já estava carente de um documento legal destinado a regulamentar o nosso sistema comercial que se apresentava em acentuado ritmo de desenvolvimento. Essa Lei permaneceu em vigor, sem nenhuma alteração por 90 anos, porém até hoje se faz presente como importante acervo de pesquisas e, mesmo, em certas tomadas de posição jurídica. Outros pontos que marcaram a segunda metade do século XIX foram (RODRIGUES, 1985):

a) A criação, em 1856, do Instituto Comercial do Rio de Janeiro em substituição à Aula de Comércio;

b) A fundação da Associação de Guarda-Livros, em 1869; 
c) A publicação de 24 números da Revista da Associação dos Guarda-Livros entre 1874 e 1875.

d) Outra Escola de Comércio começa a funcionar no Brasil em 1891, a Academia de Comércio de Juiz de Fora, Minas Gerais.

No final do século XIX a Associação de Guarda-Livros buscava a criação de um curso regular que oficializasse a profissão contábil. Assim, foi criada, em 20 de abril de 1902, a Escola Prática de Comércio, a qual, futuramente, passaria a ser denominada de Escola de Comércio Álvares Penteado, em uma homenagem a um de seus fundadores (SCHMIDT, 1996). Outras instituições contábeis fundadas na primeira metade do século XX que também merecem menção são a Escola de Comércio Mackenzie College, o Instituto Paulista de Contabilidade (atualmente denominada de Sindicato dos Contabilistas de São Paulo) e, posteriormente, a Faculdade de Economia e Administração da Universidade de São Paulo (FEA-USP).

Os diplomas expedidos pela Escola de Comércio Álvares Penteado foram oficialmente reconhecidos pelo Decreto Federal no 1.339 de 9 de janeiro de 1905, sendo reconhecidos os cursos de GuardaLivros e Perito-Contador. Para Machado (1982), esse decreto, embora seja um marco na organização do ensino comercial no Brasil, tinha na época um escopo bem mais limitado, ou seja, restringia-se a reconhecer como de utilidade pública e a organizar os cursos da Academia de Comércio do Rio de Janeiro e da Escola Prática de Comércio de São Paulo.

Em 30 de junho de 1931, foi assinado o Decreto no 20.158 que reorganizou o ensino comercial brasileiro. O Decreto determinava o recebimento do diploma de bacharel em ciências econômicas para aqueles que completassem o curso superior de administração e finanças com duração de três anos, para aqueles que concluíssem o curso técnico de dois anos receberiam o título de GuardaLivros e seria concedido o título de perito contador para os que concluíssem o curso técnico de três anos (BACCl, 2002). Posteriormente, o Decreto-Lei no 7.988/45 consolidou ensino técnico em grau superior, sendo instituído o curso de nível universitário de ciências contábeis e atuariais (CAMARGO, 1991).

Outro marco da história da Contabilidade brasileira ocorreu em 27 de maio de 1946 com a promulgação do Decreto-lei no 9295 que determinava a criação do Conselho Federal de Contabilidade (CFC) e dos Conselhos Regionais de Contabilidade (CRC) destinados a fiscalizar o exercício das profissões de Contador (Bacharel em Ciências Contábeis) e de Guarda-Livros (Técnico em Contabilidade) (HERMES, 1986).

Rodrigues (1996) relata que o Decreto-lei no 9295 foi resultado das discussões da I Convenção Nacional dos Contabilistas realizado no Rio de Janeiro em 1945, onde foi apresentado seu anteprojeto por Paulo Lyra Tavares que se tornou o primeiro presidente do CFC. O artigo 6o do Decreto-Lei no9295 determina as atribuições do Conselho Federal de Contabilidade, sendo estas:

a) organizar o seu Regimento Interno;

b) aprovar os Regimentos Interno organizados pelos Conselhos Regionais, modificando o que se tornar necessário, a fim de manter a respectiva unidade de ação;

c) tomar conhecimento de quaisquer dúvidas suscitadas nos Conselhos Regionais e dirimi-las;

d) decidir, em última instância, recursos de penalidade imposta pelos Conselhos Regionais;

e) publicar o relatório anual de seus trabalhos, em que deverá figurar a relação de todos os profissionais registrados. 
O artigo 10 do Decreto-Lei no9295 determina as atribuições dos Conselhos Regionais:

a) expedir e registrar a carteira profissional prevista no artigo 17 (Alínea a com redação dada pela Lei no 9.710, de 3 de setembro de 1946);

b) examinar reclamações a representações escritas acerca dos serviços de registro e das infrações dos dispositivos legais vigentes, relativos ao exercício da profissão de contabilista, decidindo a respeito;

c) fiscalizar o exercício das profissões de contador e guarda-livros, impedindo e punindo as infrações, e bem assim, enviando às autoridades competentes minuciosos e documentados relatórios sobre fatos que apurarem, e cuja solução ou repressão não seja de sua alçada;

d) publicar relatório anual de seus trabalhos e a relação dos profissionais registrados;

e) elaborar a proposta de seu regimento interno, submetendo-o à aprovação do Conselho Federal de Contabilidade;

f) representar ao Conselho Federal Contabilidade acerca de novas medidas necessárias, para regularidade do serviço e para fiscalização do exercício das profissões previstas na alínea $b$, deste artigo; $e$

g) admitir a colaboração das entidades de classe nos casos relativos à matéria das alíneas anteriores.

O referido Decreto-Lei também estabeleceu duas categorias profissionais, o técnico em Contabilidade e o contador, sendo registrados junto aos conselhos regionais em observância a legislação vigente, mas sendo respeitados os direitos adquiridos através de legislações anteriores (MACHADO, 1982).

\section{METODOLOGIA DA PESQUISA}

Tendo como objetivo apresentar as principais realizações do Sistema CFC/CRCs no desenvolvimento e evolução da Contabilidade brasileira, este estudo se utiliza do método historiográfico, cuja utilização, conforme Vergara (2010, p. 119), "visa ao resgate dos acontecimentos e das atividades humanas ao longo do tempo, possibilitando desvendar e compreender as mudanças, as contradições e as tendências da realidade social". Segundo Goldman (1994), a utilização da historiografia como método de pesquisa viria a possibilitar uma análise contextualizada das organizações humanas, inserindo-as em uma relação com a própria sociedade.

Mesmo não sendo um dos métodos mais presentes no campo das Ciências Sociais Aplicadas, principalmente da Contabilidade, observa-se durante a última década um movimento em vista de sua promoção e disseminação entre esses pesquisadores (por exemplo, PELEIAS E BACCl, 2004; FARIA, 2004; PELEIAS, SILVA, SEGRETI E CHIROTTO, 2007; MENDONÇA NETO, CARDOSO, RICCIO E SAKATA, 2008; GONÇALVES, 2010; OTT E BARBOSA, 2011).Tal promoção, possivelmente, seja fruto tanto do reconhecimento das contribuições oriundas de sua aplicação como da carência de pesquisas históricas que contemplem a complexidade deste campo de estudo.

Porém, ressalva Vergara (2010), é preciso cautela na sua utilização tendo em vista que esse método possui duas vertentes distintas: a historiografia clássica, ou velha história, predominante até o século XIX, que se caracteriza pela narrativa dos acontecimentos com base na análise dos documentos escritos e acontecimentos conjunturais; e a nova história, ou história total, mais fortemente utilizada a partir do século XX, que se caracteriza pela análise das estruturas e abrange todas as atividades humanas, utilizando outras fontes de coletas de dados além da análise de documentos, tendo em vista a precisão da investigação. Existe um embate entre os pesquisadores de ambas as abordagens, 
com críticas mútuas às limitações dessas duas vertentes, mas que acaba por incorrer muito mais em uma complementaridade de ambas as visões do que em uma necessidade de exclusão, como defende Tuchman (2003).

Nesta pesquisa, cujo foco se concentra na reconstrução histórica do desenvolvimento e atuação do sistema CFC/CRCs no Brasil, se empregou a historiografia clássica, a qual, conforme Brito (2003, p. 11, marcações do autor), caracteriza-se da seguinte forma:

ao historiador bastaria reconstruir os fatos como eles "realmente se passaram", portanto, nada de julgamentos, nem de buscar, no exame do passado, lições para o presente; ao historiador caberia uma postura de neutralidade, já que entre ele e seu objeto não haveria interdependência alguma; a história/passado existiria objetivamente e poderia ser captada através dos documentos; ao historiador caberia reunir o maior número de documentos, atento à sua autenticidade; os fatos deveriam ser extraídos desses documentos, organizados e apresentados numa narrativa que respeitasse sua seqüência cronológica.

Deste modo, quanto ao método de coleta de dados para esta fase de pesquisa histórica nos moldes da abordagem clássica, esta coleta de dará mediante pesquisa documental. De acordo com Godoy (1995), a principal diferença entre a pesquisa bibliográfica e a pesquisa documental reside na variedade de documentos com possibilidade de uso para extração de dados por parte desta última, que pode incluir: diários, cartas, memorandos, relatórios, estatísticas e elementos iconográficos. Neste contexto, Gil (2010) destaca, nomeadamente, os registros institucionais escritos como importantes fontes documentais, sendo eles: projetos de lei, relatórios de órgãos governamentais, atas de reuniões, sentenças judiciais, documentos registrados em cartórios, etc.

Dentre essas opções, a reconstrução da história do sistema CFC/CRCs se baseará, principalmente, nas informações contidas nos relatórios internos do próprio Conselho Federal de Contabilidade e de seus Conselhos Regionais. Estes relatórios, produzidos ao longo de toda a história do CFC, reúnem um grande leque de informações a respeito da atuação do CFC junto aos profissionais da Contabilidade no país, sendo, portanto, fundamentais para o desafio de apresentar essa história. Em complemento, também serão utilizados documentos de comunicação do CFC e CRCs, como jornais, revistas e boletins institucionais que guardam acontecimentos marcantes dos sessenta e seis anos de história desta entidade.

Com relação ao horizonte temporal no qual se insere esta reconstrução histórica, este é compreendido entre os anos de 1946, quando houve a criação do Conselho Federal de Contabilidade, e de 2012, ano de comemoração do sexagésimo sexto aniversário de sua atuação no país. Para construção da história do sistema CFC/CRCs, exposta no capítulo seguinte, são ressaltados, a partir da criação deste sistema institucional, os seguintes tópicos: criação do código de ética profissional do contabilista; transferência da sede para Brasília e construção do edifício-sede; processo de alteração na regulamentação da profissão; Lei da representatividade. Por fim, é traçada uma linha histórica com foco na criação dos Conselhos Regionais de Contabilidade, com destaque para seus primeiros presidentes e características de sua implantação e ação atual.

\section{O SISTEMA CFC/CRCS: DESENVOLVIMENTO E ATUAÇÃO EM UMA PESQUISA DOCUMENTAL}

Com a publicação do Decreto-Lei no 9.295, em 27 de maio de 1946, foram criados os Conselhos Federal (CFC) e Regionais (CRCs) de Contabilidade. Concomitantemente, a profissão ganhou regulamento próprio, instituindo-se o princípio básico de que tudo o que envolve a matéria contábil constitui prerrogativa privativa dos contabilistas. Entre outras atribuições, ao CFC coube a competência de disciplinar as atividades dos Conselhos, com a finalidade de manter a unidade da 
estrutura federativa. Dessa forma, as atividades operacionais e administrativas dos Conselhos, em seu conjunto, passaram a ser realizadas de forma que não houvesse discrepância nos atos executados pelo CFC e CRCs, embora os Regionais mantivessem autonomia no que se refere à administração de seus serviçoes, gestão de recursos, regime de trabalho e relações empregatícias.

Diante da necessidade de analisar a influência do sistema CFC/CRCs no desenvolvimento da Contabilidade brasileira, nesta sessão serão apresentadas as principais contribuições e fatos que marcaram a história deste agente no contexto da Contabilidade do Brasil. Para tanto, foram reunidas informações contidas nos relatórios internos do próprio Conselho Federal de Contabilidade e de seus Conselhos Regionais, disponibilizados para a realização deste estudo. Em complemento, também serão utilizados documentos de comunicação do CFC e CRCs, como jornais, revistas e boletins institucionais que contêm registros de acontecimentos marcantes dos sessenta e seis anos de história desta entidade.

\subsection{CÓDIGO DE ÉTICA PROFISSIONAL DO CONTABILISTA}

A conduta profissional, a exemplo das ações humanas, deve transcorrer dentro dos limites estabelecidos pelos parâmetros morais que são inerentes à vida em sociedade. Para garantir que o bem-estar comum se sobrepusesse aos interesses individuais, o exercício profissional fidedigno passou a aplicar, ao longo dos anos, uma ciência vinculada a julgamento de apreciação moral e juízos de valor, estruturou-se em códigos deontólogos, especificando os deveres de cada profissão, e tornou-se instrumento de proteção do exercício dos profissionais, ao mesmo tempo em que resguarda os direitos dos públicos assistidos.

$\mathrm{Na}$ área contábil, o primeiro ensaio de agrupamento de normas relativas à ética profissional, formatado nos moldes de um código, ocorreu em 1950, durante o V Congresso Brasileiro de Contabilidade, realizado em Belo Horizonte (MG), ocasião em que se deu por aprovado o "Código de Ética Profissional do Contabilista". Esse documento, embora não tivesse alcançado o caráter de normatização pelo Conselho Federalde Contabilidade, demonstrou a preocupação dos contabilistas com a garantia de que a atuação profissional fosse feita dentro dos padrões reconhecidamente corretos. Note-se que esse código surgiu poucos anos após a publicação do Decreto-Lei no 9.295/46, que regulamentou a profissão dos contabilistas no Brasil.

Muitos debates se sucederam em relação à regulamentação ética da profissão, até que, em 4 de setembro de 1970, o CFC publicou a Resolução CFC no 290, instituindo o Código de Ética Profissional do Contabilista.

Princípios, hábitos e costumes evoluem no tempo, assim como as profissões se ajustam à evolução econômica e social dos países. Em função, da intensificação do relacionamento do profissional da Contabilidade com a sociedade e com o próprio grupo profissional, o CFC aprovou, em 10 de outubro de 1996, a Resolução no 803, que revogou a anterior e instituiu o novo Código de Ética Profissional do Contabilista. Posteriormente, algumas atualizações foram necessárias e essas alterações foram introduzidas no texto do Código pelas Resoluções CFC no 819/97 e 942/02.

A finalidade desse estatuto os contabilistas encontram logo no seu primeiro artigo: "Este Código de Ética Profissional tem por objetivo fixar a forma pela qual se devem conduzir os contabilistas, quando do exercício profissional". Ao todo são 14 artigos, divididos em cinco capítulos que tratam: I - Do objetivo; II - Dos deveres e das proibições; III - Do valor dos serviços profissionais; IV - Dos deveres em relação aos colegas e à classe; e $\mathrm{V}$ - Das penalidades.

A normatização ética promovida pelo CFC, ao longo das últimas quatro décadas, não significa um compromisso de virtude abstrata, mas sim, a implantação de um sistema de princípios morais destinados a governar as relações dos integrantes da profissão entre si e as que os contabilistas mantêm com os clientes e com a sociedade, de modo geral. O mecanismos do estatuto opera como 
um sistema de partidas dobradas, no qual todos têm direito ao dever de exercer a profissão com honestidade, probidade e correção.

\subsection{TRANSFERÊNCIA DA SEDE PARA BRASÍLIA E CONSTRUÇÃO DO EDIFÍCIO-SEDE}

A virada da década de 1980, movida pelos ventos da abertura política, prenunciava profundas mudanças no cenário nacional. Uma nova Constituição nascia a 5 de outubro de 1988, num clima de geral euforia, tão apressado quanto pródigo em assegurar direitos constitucionais e toda a espécie de benefícios, em nome das liberdades democráticas. Denominada de "Constituição Cidadã", a nova Ordem, de fato, liberava uma ânsia de participação política e debate público, sufocados há anos na garganta dos brasileiros.

Seguem-se as mobilizações populares por eleições diretas para o Executivo; os movimentos trabalhistas; a discussão de novas políticas públicas; e as seguintes tentativas do Governo Federal em aprovar seus planos de estabilização econômica. No decorrer da década de 1990, simbolicamente, o Brasil entra noutra expectativa de transição - que é também da humanidade -, vislumbrando já, com o final do século XX, o advento de um Novo Milênio.

Nesse tempo de mudanças, o Conselho Federal de Contabilidade, instalado no Rio de Janeiro desde a sua criação, sente a necessidade de se mudar para Brasília, entre outras razões, para dar cumprimento à determinação contida no Artigo 3o do Decreto-Lei no 9.295/46, que prevê a sede do CFC na Capital da República. Assim, em 1991, foi aprovada a trasnferência desta Entidade para a Capital Federal. Presidia o Conselho o saudoso líder Ivan Carlos Gatti, em cuja gestão empolgou a classe contábil com seu arrojado Programa "Contador: a Profissão do Ano 2000".

A primeira consequência da Resolução CFC no719/91, que dispõe sobre a transferência dos servidores e dos serviços para Brasília, foi a contratação de novo quadro funcional, visto que a maioria dos funcionários optou por ficar no Rio de Janeiro. Além disso, no Plano de Metas de 1991, foi prevista a aquisição de imóvel destinado a abrigar a nova sede do CFC. No dia 4 de setembro de 1991, na Terracap-Brasília-DF, foi assinada a escritura de compra do terreno. Imediatamente, foi constituída a Comissão de Obras.

O lançamento da pedra fundamental do majestoso edifício, construído sob medida no Setor de Autarquias Sul de Brasília, para a sede própria do CFC, foi feito em cerimônia realizada no dia 19 de março de 1993. Com as presenças do ex-presidente do CFC Iberê Gilson e do entrão vice-presidente José Maria Martins Mendes, já designado Coordenador da Comissão de Obras, o então presidente do CFC, Ivan Carlos Gatti, deu início à concretização de mais um sonho da classe contábil, desta feita, uma conquista física, compatível com a grandeza social desfrutada pelos contabilistas brasileiros. Simbolizando sua paixão e amor pela família classista que abraçara, estavam presentes à singela solenidade sua esposa lara e a filha Rosana.

Definidas, estrategicamente, as necessidade funcionais do CFC e traçados os parâmetros gerais, a Comissão de Obras partiu para a realização de um concurso nacional para a escolha do melhor anteprojeto arquitetônico para a sede. Em edital de 31 de dezembro de 1991, amplamente divulgado, eram oferecidos prêmios valiosos para atrair trabalhos de alto nível, para escolha do melhor dentre os melhores. Com o apoio e divulgação de todos os CRCs, inscreveram-se 66 arquitetos, oriundos de dez Unidades da Federação, que apresentaram, no prazo estabelecido, 37 trabalhos para julgamento.

No dia 20 de março de 1992, a Comissão Julgadora apresentou ao Plenário do CFC o trabalho vencedor do arquiteto José Luiz Tabith Júnior, de São Paulo. No final de março de 1993 foram iniciadas as obras. Todos os cuidados legais e administrativos e não menos rigorosos critérios 
técnicos foram empregados na construção da obra, acompanhada, sistematicamente, pelo presidente Gatti, que verificava in loco cada laje que ia sendo concretizada.

Feita a contabilização da obra, constata-se que todos os seus custos foram pagos, exclusivamente, com dinheiro dos contabilistas. Este era um ponto de honra que o presidente Gatti fazia questão de propagar. A propósito, ele não queria que o edifício fosse batizado com o seu nome. Mas fez afixar uma placa com os dizeres: "Conselho Federal de Contabilidade. Esta sede será construída com o esforço e o dinheiro da classe contábil brasileira. Em 19 de março de 1993".

Coube à gestão seguinte, tendo na presidência o contador José Maria Martins Mendes, concluir a nova sede, dotando-a das condições de funcionalidade para acolher os conselheiros e o total de 67 funcionários que trabalhavam, então, no CFC.

Louve-se a visão de futuro dos construtores de tão elogiável obra. Sua estrutura racional, com uma relação de custos versus benefícios altamente favorável, vem permitindo e permitirá, ainda, por muitas décadas, mediante pequenas intervenções e articulações de suas divisórias móveis, atender com segurança, conforto e racionalidade a todas as demandas a que se destina.

Ademais, com a nova localização da sede, o CFC deu um salto na sua trajetória institucional, abdicando da herança burocratizante da Administração Pública. Ascendendo a um elevado patamar de qualidade, assumiu um modelo de Administração Gerencial mais flexível, com base em projetos e metas mais ousados e ao mesmo tempo exequíveis.

Na esteira da modernidade administrativa, são aprovadas políticas de planejamento dentro da visão sistêmica. Os dirigente adotam na administração da sua entidade o conhecido conceito de Sistema CFC/CRCs, a ser aprofundado mais adiante. Dessa forma, os CRCs, nivelados por cima, em todo o território nacional, ganharam nova dinâmica. Essa vital mudança de paradigma tem permitido às sucessivas gestões, federal e regionais, adaptarem-se, tempestivamente, sem maiores transtornos, adequando a estrutura organizacional e a composição de suas equipes às exigências do serviço, detectadas no ambiente dinâmico do seu grande público institucional, mormente, os profissionais da Contabilidade.

\subsection{PROCESSO DE ALTERAÇÃO NA REGULAMENTAÇÃO DA PROFISSÃO}

Com os anos, a regulamentação trazida pelo Decreto-Lei no 9.295/46 passou por algumas alterações, como as implementadas pelos Decretos-Leis no 9.710, de 3 de setembro de 1946, e № 1.040, de 21 de outubro de 1969. Porém, com o desenvolvimento da profissão e a modernização das relações da classe contábil com a sociedade, contadores, técnicos em Contabilidade e empresários da área passaram a pleitear a modernização da principal legislação profissional.

Assim, no dia 22 de maio de 2006, quando foi assinada a Portaria CFC no 44, instituindo uma comissão nacional para reformular o Decreto-Lei no 9.295/46, deu-se início a um processo considerado um marco histórico para o Sistema que reúne o CFC e os CRCs: o texto da lei de regência da profissão contábil seria submetido a uma atualização e comportaria as reformas necessárias ao desempenho profissional nos dias atuais.

Com a missão principal de alinhavar um texto de reforma do Decreto-Lei e promover a articulação com os Conselhos Regionais de Contabilidade para levantar os anseios dos profissionais de todo o país, a comissão nacional instituída pela então presidente do CFC, Maria Clara Cavalcante Bugarim, foi composta por profissionais com efetiva experiência e conhecimento da área. Para possibilitar a ampla participação da classe, foram criadas também comissões nos 26 estados e no Distrito Federal.

A primeira minuta do anteprojeto, denominada versão 01 , foi disponibilizada à sociedade por meio de audiência pública, no período de 1으 de dezembro de 2006 a 19 de janeiro de 2007. Contadores, 
técnicos em Contabilidade e demais interessados puderam conhecer a proposta e apresentar as suas sugestões que, posteriormente, foram analisadas pelas comissões estaduais e pela nacional.

Fruto do persistente esforço de gestão participativa, o processo de reforma da lei de regência da profissão entrou em 2007 incorporando o saldo das sicussões e, mais uma vez, após elaboração de nova minuta - a versão 02 - , foi aberta uma audiência pública, ocorrida de 10 de maio a 15 de junho. Com as novas sugestões, o anteprojeto foi arrematado pela comissão nacional e submetido ao Plenário do CFC.

Para reformulação do Decreto-Lei no 9.295/46, o Sistema CFC/CRCs entendeu que seria necessário levantar um panorama nacional dos anseios dos profissionais, disponibilizando canais de participação direta, para que houvesse o maior consenso possível. Ao final do processo, a comissão nacional pôde concluir que as duas audiências públicas foram muito importantes, em primeiro lugar, para a discussão dos aspectos mais polêmicos da proposta de reformulação do Decreto-Lei.

Esse processo, da forma como foi conduzido, buscando a renovação da lei de regência da profissão contábil a partir da mais ampla participação e representatividade, demonstra o amadurecimento e o fortalecimento institucional alcançado pelo Sistema CFC/CRCs.

\subsection{LEI DA REPRESENTATIVIDADE}

Nas reuniões plenárias mensais do CFC se constata, guardadas as devidas proporções, o que significa, na prática, a forma federativa de poder. Ao mesmo tempo em que o Plenário atua como um corpo único, em nome do interesse maior da classe contábil brasileira, cada conselheiro, oportunamente, representa as questões relativas à realidade do seu ente federativo.

Mas esse nível de abrangência, que engloba toda a federação - os 26 estados e o Distrito Federal -, nem sequer esteve presente nos 60 anos de história do CFC. Pelo contrário, trata-se de uma conquista que chegou às vésperas da comemoração do sexagésimo aniversário de criação dos Conselhos de Contabilidade. Até 2005, o Plenário do CFC era composto por 15 membros, com igual número de suplentes, conforme estabelecido no Decreto-Lei no 1.040, de 21 de outubro de 1969.

Após ampla campanha no Congresso Nacional para aumentar a representatividade dos entes federativos no seu Plenário, o CFC finalmente obteve vitória em agosto de 2005, quando houve a sanção pelo presidente da República Luiz Inácio Lula da Silva da Lei no 11.160, alterando o caput do Decreto-Lei no 1.040/69, que passou a ter a seguinte redação:

Art. 1ㅇ O Conselho Federal de Contabilidade - CFC será constituído por 1 (um) representante efetivo de cada Conselho Regional de Contabilidade - CRC, e respectivo suplente, eleitos para um mandato de 4 (quatro) anos, com renovação a cada biênio, alternadamente, por $1 / 3$ (um terço) e 2/3 (dois terços).

É importante destacar também que, além do aumento no número de representantes, a Lei no 11.160/05 estabeleceu a renovação na composição do Plenário seja feita de forma alternada, o que possibilita a continuidade dos trabalhados sem que haja perda de tempo motivada pela interrupção conjunta dos mandatos dos conselheiros. Dessa forma, esta Lei da Representatividade, especialmente, veio ao encontro de umas das aspirações democráticas mais legítimas da Entidade.

\subsection{CONSELHOS REGIONAIS DE CONTABILIDADE: CARACTERÍSTICAS E ASPECTOS PRINCIPAIS}

Atualmente, com 66 anos de história, o Sistema CFC/CRCs contabiliza 28 entidades, todas estabelecidas em adequadas sedes-próprias. São 27 Conselhos Regionais - cada qual 
representando, legalmente, uma das unidades federativas - , todos com direito a voz e voto no Plenário do Conselho Federal de Contabilidade, com sede em Brasília - DF.

Com a democratização das conquistas, um valor histórico sabiamente preservado, percebe-se hoje uma eficaz integração entre Conselhos Regionais experientes (criados em 1946) e incipientes (criados em 1995); grandes e pequenos; com 100.000 profissionais registrados ou apenas $1 \%$ desse quadro; mas todos interessados em nivelar por cima.

A construção de um imensurável patrimônio institucional foi feita, exclusivamente, com recursos próprios da classe contábil. Sua grandeza emana da capacidade política dos contabilistas de fazerem associação. Agregando em torno de 400 mil profissionais, o sistema mantém-se sempre unido em torno do objetivo comum de servir à sociedade brasileira.

Quando o presidente Eurico Gaspar Dutra assinou o Decreto-Lei no 9.295, no dia 27 de maio de 1946, a história da Contabilidade no Brasil começou a ser construída por meio de bases sólidas. Fruto da persistência dos primeiros representantes da classe contábil recém-instituída legalmente, a representação dos Conselhos Regionais de Contabilidade foi, aos poucos, ocupando o território nacional e, na década de 1990, chegou a todos os entes federativos.

O Conselho Federal de Contabilidade teve sede imediatamente instalada no Rio de Janeiro, onde permaneceu até 1996, sendo transferida para Brasília. Como relatado anteriormente, a construção do prédio próprio do CFC na capital federal foi iniciada em 1993, na gestão do presidente Ivan Carlos Gatti, e inaugurada em 1996, pelo então presidente José Maria Martins Mendes.

O primeiro CRC a ser criado foi o do Paraná, em 15 de junho de 1946. O contador Carlos Sternberg Valle foi o primeiro presidente do CRCPR. Em 2006, ano em que os Conselhos de Contabilidade completavam 60 anos de sua lei de regência, O CRC paranaense representava cerca de 24 mil profissionais contábeis no estado.

O CRC de Santa Catarina veio poucos meses depois, em 8 de dezembro de 1946, e seu primeiro presidente foi Lindolfo Anatércio Gonçalves Pereira. Atualmente, o CRCSC conta com mais de 15 mil contabilistas registrados.

Em seguida, poucos dias depois, em 14 de dezembro de 1946, foi criado o Conselho Regional de Contabilidade de São Paulo, tendo como presidente Pedro Pedreschi. No início deste século XXI, o CRCSP é o maior Regional do país, contando com aproximadamente 100 mil profissionais registrados.

Já o Conselho Regional de Contabilidade do Rio de Janeiro apresenta uma peculiaridade histórica: antes da criação do CRCRJ, existiam dois Conselhos Regionais, um no antigo estado do Rio de Janeiro e outro no antigo estado da Guanabara. O CRCRJ criado no antigo estado do Rio de Janeiro foi criado no dia 21 de dezembro de 1946, e seu primeiro presidente foi o contador Emílio Dias Filho. Quanto ao extinto CRC da Guanabara, surgiu em seu lugar o CRC do Distrito Federal, transferido para a nova capital da república - Brasília. Atualmente, o CRCRJ conta com 49 mil contabilistas.

A representação dos Conselhos de Contabilidade no Nordeste começou com Sergipe. No dia 31 de janeiro de 1947, foi criado o CRCSE, cujo primeiro presidente foi Josino Marques de Almeida. O CRC sergipano possui em torno de três mil e quinhentos profissionais registrados.

O próximo CRC a ser instalado foi o da Bahia em de fevereiro de 1947. Tendo como seu primeiro presidente o contador João Evangelista de Moraes Ramos, o CRCBA conta atualmente com cerca de quinze mil contabilistas.

No dia seguinte, em 8 de fevereiro de 1947, foi criado o Conselho Regional de Contabilidade de Pernambuco, assumindo como seu primeiro presidente João Cícero Valença. Hoje, são quase nove mil profissional inscritos no CRCPE. 
O Conselho Regional de Contabilidade de Minas Gerais veio pouco tempo depois. Instalado em 18 de abril de 1947, o CRCMG foi presidido inicialmente pelo contador Ismail Corrêa e Castro. Hoje, possui 44 mil profissionais registrados.

No Rio Grande do Sul, o Conselho Regional de Contabilidade foi criado em 25 de abril de 1947. O primeiro presidente foi o contador Henrique Desjardins. Mais de 30 mil profissionais estão registrados no CRCRS.

No dia 27 de maio de 1947, houve a instalação do primeiro CRC no Norte do país. O Conselho Regional de Contabilidade do Pará iniciou com a presidência de Renato da Motta Barbosa. Hoje, o CRCPA soma mais de sete mil registros profissionais.

Nesse mesmo ritmo, seguiram-se as criações dos CRCs dos demais estados. Em 1o de junho de 1947, foi a vez do Conselho Regional de Contabilidade de Alagoas. Seu primeiro presidente foi o contador Samuel Lima. Atualmente, o CRCAL possui quase quatro mil profissionais registrados.

O Conselho Regional de Contabilidade do Ceará foi criado em 7 de junho de 1947 e seu primeiro presidente foi Francisco Aprígio Riquet Nogueira. Há mais de dez mil profissionais registrados no CRCCE.

No Centro-Oeste do Brasil, o primeiro Conselho Regional de Contabilidade a ser nstalado foi o de Mato Grosso, em 11 de setembro de 1947. O presidente, nessa data, era o contador Aecim Tocantins. O CRCMT conta com mais de sete mil profissionais inscritos.

No Piauí, o Conselho Regional de Contabilidade foi criado em 6 de dezembro de 1947. O primeiro presidente foi o contador Pedro Tobias Duarte. Hoje, há mais de quatro mil profissionais registrados no CRCPI.

Em 11 de agosto de 1948, inaugurou-se o Conselho Regional de Contabilidade do Rio Grande do Norte, na época presidido por Jurandir Sitaro da Costa. Atualmente, o CRCRN conta com quase quatro mil profissionais registrados.

O Conselho Regional de Contabilidade do Espírito Santo foi inaugurado no dia 20 de novembro de 1948 , tendo à frente o presidente Pedro Vieira de Andrade. Quase nove mil profissionais estão hoje registrados no CRCES.

O Maranhão ganhou a instalação do seu Conselho Regional de Contabilidade em 25 de novembro de 1948. O primeiro presidente foi Antonio Leôncio Machado. Atualmente, o CRCMA conta com quase quatro mil profissionais registrados.

Sob a presidência de Orlando Lemos Falcone, o Conselho Regional de Contabilidade do Amazonas foi criado em 4 de março de 1950. O CRCAM conta com quase seis mil profissionais registrados atualmente.

Em 30 de março de 1960, ano da inauguração da capital federal, foi instalado o Conselho Regional de Contabilidade do Distrito Federal, sob a presidência de Amaro Soares de Andrade. Hoje, possui quase treze mil profissionais registrados.

Uma década se passou até que, em 26 de outrubro de 1970, foi inaugurado o Conselho Regional de Contabilidade do Estado da Paraíba. O seu primeiro presidente foi o contador Marcos de Lima Nevez. Atualmente, há mais de cinco mil profissionais registrados no CRCPB.

Mato Grosso do Sul, que se tornou estado em 10 de janeiro de 1979, ganhou o seu Conselho Regional de Contabilidade em 17 de maio de 1985. O Presidente do CRCMS, naquela época, era Wilson Marques Barbosa. Hoje, o Regional possui mais de cinco mil profissionais inscritos. 
Na década de 1990 foram instalados os cinco últimos CRCs, todos na região Norte. Em Rondônia, o CRC foi criado no dia 21 de junho de 1991, e seu primeiro presidente foi o contador Antônio Silvado Canhin. Hoje, o CRCRO possui cerca de três mil profissionais registrados.

No Tocantins, o CRC foi criado em 22 de outubro de 1992 e seu primeiro presidente foi o contador Moisés Vieira Labre. Atualmente, há mais de dois mil profissionais registrados no CRCTO. O Conselho Regional de Contabilidade do Amapá foi instalado no mesmo dia, em 22 de outubro de 1992, sob a presidência de José Paulo da Silva Ramos. O CRCAP conta com aproximadamente mil e duzentos profissionais inscritos.

Na data de 21 de julho de 1995 foi criado o Conselho Regional de Contabilidade do Acre, na época presidido pelo contador Manoel Correia de Lima Neto. Atualmente, o CRCAC conta com cerca de mil e cem profissionais registrados.

Por fim, o Conselho Regional de Contabilidade de Roraima foi criado de 24 de julho de 1995. O seu primeiro presidente foi o contador Manoel Dantas Dias, e o CRCRR conta hoje com cerca de setecentos profissionais registrados.

Na Figura 1, a seguir, é apresentado um resumo dessa evolução histórica da criação dos diversos $\mathrm{CRCs}$, conforme narrado anteriormente.

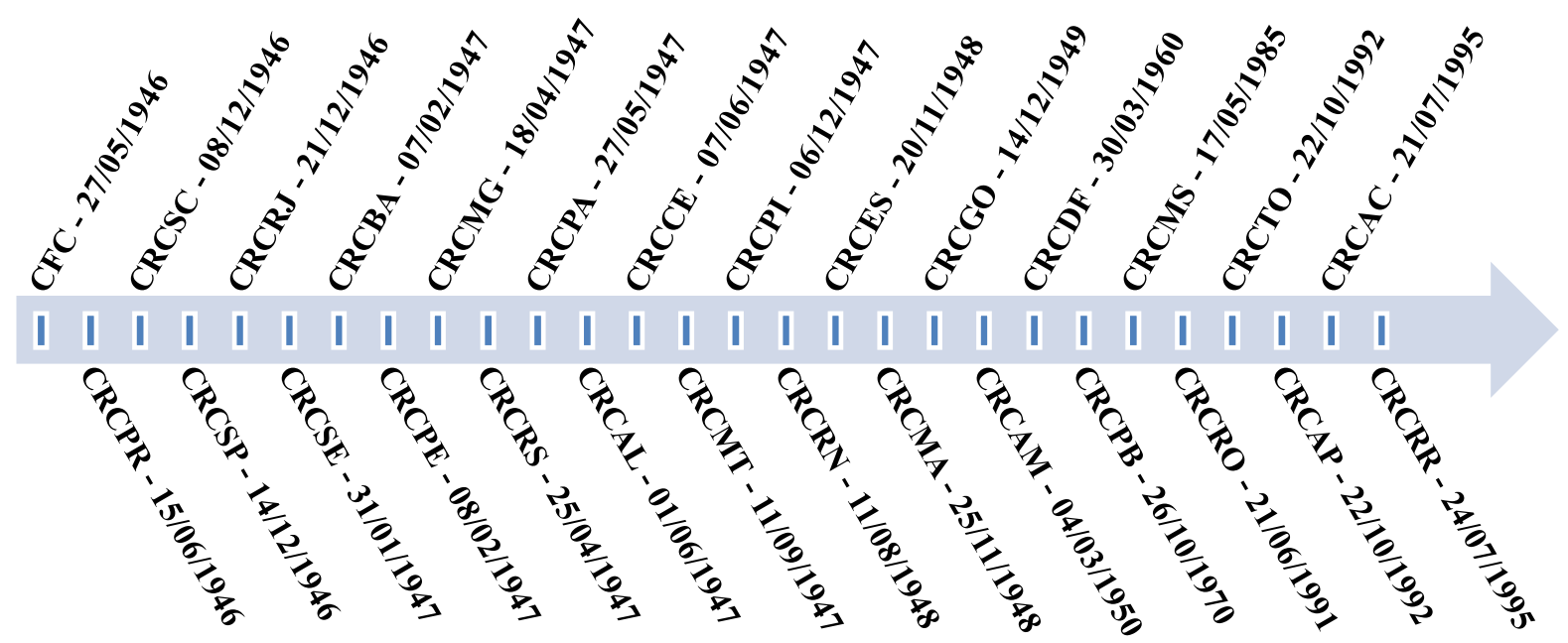

Figura 1: Cronologia de criação dos CRCs.

Fonte: Elaborada pelos autores.

\section{CONSIDERAÇÕES FINAIS}

O exercício de investigação histórica, desenvolvido ao longo deste trabalho, constitui-se como um esforço científico importante no sentido de resgatar eventos cruciais para o desenvolvimento da Contabilidade no Brasil, ressaltando o papel do Conselho Federal de Contabilidade e Conselhos Regionais nessa evolução. Partindo do seu objetivo geral de apresentar as principais realizações do Sistema CFC/CRCs no desenvolvimento e evolução da Contabilidade no país, pôde ser observada a participação dessa instituição ao longo das últimas décadas, principalmente no que se refere à incorporação de transformações essenciais no exercício profissional dos bacharéis e técnicos em Contabilidade.

Inicialmente, a revisão bibliográfica que se concentrou na história da Contabilidade no Brasil evidenciou conquistas importantes nos primeiros séculos do país, como: a criação da primeira escola de Comércio, em 1756; a fundação da Associação de Guarda-Livros, em 1869; e a criação de outras instituições de ensino contábil, como a Escola Prática de Comércio, a Escola de Comércio Mackenzie 
College, o Instituto Paulista de Contabilidade e a Faculdade de Economia e Administração da Universidade de São Paulo, no início do século XX. Essa primeira fase histórica da Contabilidade no Brasil tem seu final em 1946, exatamente com a criação do Conselho Federal de Contabilidade.

De fato, desde a sua criação, a atuação do Conselho Federal e Conselhos Regionais se mostra como fundamental para a evolução das práticas contábeis no país. Na pesquisa documental, ao serem ressaltados aspectos referentes à criação do código de ética profissional do contabilista, o processo de alteração na regulamentação da profissão e a criação da lei da representatividade, enfatiza-se a preocupação da entidade com a evolução das práticas contábeis no país, de forma a acompanhar as tendências internacionais do campo. Além disso, a transferência e criação de um edifício-sede do CFC na capital federal evidenciam a importância e o peso que suas ações têm para o desenvolvimento não apenas da profissão, mas também do próprio país. Da mesma forma, é possível perceber que a história de criação dos Conselhos Regionais de Contabilidade, que se deu ao longo dos primeiros cinquenta anos de história do CFC, se constitui como um reflexo da história de desenvolvimento do país, em um movimento que se inicia nas capitais litorâneas do sul e sudeste e avança para as regiões nordeste, norte e interiores do Brasil.

Ademais, é importante destacar que essa pesquisa se constitui muito mais de um esforço inicial na reconstrução histórica deste agente-chave da Contabilidade Brasileira do que um empreendimento finalizado. Apesar de sua contribuição se mostrar fundamental para a evolução do conhecimento no campo das Ciências Contábeis, permitindo observar que a evolução da história do país é acompanhada pelo desenvolvimento da Contabilidade nacional, tendo o CFC como personagem principal dessa história, não se esgotam as possibilidades de investigação oriundas deste tema. Desse modo, é preciso enfatizar a necessidade de complementar os achados e discussões aqui apresentados com a utilização de outras fontes históricas de informações, como, por exemplo, a experiência de profissionais que vivenciaram as transformações e eventos apresentados neste estudo.

\section{Referências}

AGRIZZI, D.; SIAN, S. Professionalisation in a centralised state: the development of accountancy in Brazil. In: APIRA - ASIA PACIFICA INTERDISCIPLINARY RESEARCH IN ACCOUNTING, Sydney, AU, 12 - 13 jul. 2010. Anais...

BACCI, J. Estudo Exploratório sobre o Desenvolvimento Contábil Brasileiro: uma Contribuição ao Registro de sua Evolução Histórica. 175p. 2002. Dissertação (Mestrado em Controladoria e Contabilidade Estratégica). Fundação Escola de Comércio Álvares Penteado, São Paulo.

BRASIL. Lei no 11.638 de 28/12/2007. Disponível em: <http://www.cvm.gov.br>. Acesso em 10 out. 2012.

BRITO, E. Z. O campo historiográfico: entre o realismo e as representações. Universitas $F A C E$, v. 1, n. 1, p. 9-24, 2003.

BUESA, N. Y. A Evolução Histórica da Contabilidade como Ramo do Conhecimento. Revista Eletrônica Gestão e Negócios, v. 1, n. 1, 2010.

CAMARGO, Y. A. O ensino da Contabilidade e o futuro da profissão. Revista CRCRS, Porto Alegre, v. 20, n. 66, p. 39-46, 1991.

CARNEGIE, G. D.; RODRIGUES, L. L. Exploring the dimensions of the international accounting history community. Accounting History, v. 12, n. 4, p. 441-464, 2007.

FARIA, A. R. Relevância, conteúdo e metodologia na investigação histórica em Contabilidade. Revista de Contabilidade e Comércio, v. 60, n. 237, p. 195-224, 2004. 
GIL, A. C. Métodos e técnicas de pesquisa social. 6. ed. São Paulo: Atlas, 2010.

GODOY, A. S. Pesquisa qualitativa: tipos fundamentais. Revista de Administração de Empresas, São Paulo, v. 35, n. 3, p. 20-29, 1995.

GOLDMAN, P. Searching for history in organizational theory: comment on Kieser. Organization Science, v. 5, n. 4, 1994.

GONÇALVES, M. Â. Bosquejo duma sucinta história da Contabilidade em Portugal até a fundação da primeira escola de comércio e Contabilidade (1759). Revista Universo Contábil, v. 6, n. 4, p. 89-103, 2010.

HERMES, G. O bacharel em ciências contábeis. Brasília: Senado Federal. Centro Gráfico, 1986.

LIRA, M. C. A evolução da contabilidade pública em Portugal até o século XVIII. Contabilidade, Gestão e Governança, v. 14, n. 3, p. 34-45, 2011.

MACHADO, N. O ensino de contabilidade nos cursos de ciências contábeis na cidade de São Paulo. 1982. Dissertação (Mestrado em Administração). Escola de Administração de Empresas de São Paulo Fundação Getúlio Vargas, São Paulo.

MARTINS, M. F. O. Um passeio na contabilidade: da pré-história ao novo milênio. Adcontar, v. 2, n. 1, p. 7-10, 2001.

MENDONÇA NETO, O. R.; CARDOSO, R. L.; RICCIO, E. L.; SAKATA, M. C. A Contabilidade a serviço do nazismo: uma análise da utilização da Contabilidade como instrumento de exercício de poder. Revista de Contabilidade da Ufba, v. 2, n. 2, p. 4-14, 2008.

NIYAMA, J. K.; SILVA, C. A. T. Contabilidade e seu ambiente no Brasil. Brazilian Business Review, v. 2, n. 1, p. 13-32, 2005.

OTT, E.; BARBOSA, M. A. Uma contribuição à historiografia do ensino contábil no Estado do Rio Grande do Sul. Revista de Educação e Pesquisa em Contabilidade, v. 5, Ed. Especial, p. 77-99, 2011.

PELEIAS, I. R.; BACCI, J. Pequena cronologia do desenvolvimento contábil no Brasil: os primeiros pensadores, a padronização contábil e os congressos brasileiros de Contabilidade. Revista Administração On Line - FECAP, v. 5, n. 3, p. 39-54, 2004.

PELEIAS, I. R.; SILVA, G. P.; SEGRETI, J. B.; CHIROTTO, A. R. Evolução do ensino da Contabilidade no Brasil: uma análise histórica. Revista de Contabilidade e Finanças, Ed. Especial, p. 19-32, 2007.

PEREIRA, F. I. Em busca do berço da Contabilidade no mundo sul-americano. In: SIMPÓSIO DE EXCELÊNCIA E GESTÃO DE TECNOLOGIAS, 3, 2006. Anais...

PIGATTO, J. A. M.; LISBOA, L. P. Evolução e atual estado da Contabilidade alemã. Caderno de Estudos FIPECAFI, n. 21, 1999.

RODRIGUES, A. A. A História da profissão contábil e das instituições de ensino, profissionais e culturais da Ciência Contábil no Brasil. Revista do CRCRS, Porto Alegre, v. 14, n. 43, p. 34-52, set./dez. 1985.

RODRIGUES, A. A. Cinquenta anos da Lei de regência da profissão contábil no Brasil. Revista do CRCRS, Porto Alegre, v. 25, n. 86, p. 43-45, jul./set. 1996.

RODRIGUES, J. M. Contabilidade na China: evolução histórica e análise da aderência da normatização contábil aos padrões internacionais do IASB. 2007. Dissertação (Mestrado). Programa Multiinstitucional e Inter-Regional de Pós-Graduação em Ciências Contábeis, Brasília.

RODRIGUES, L. L.; GOMES, D. Evolução da profissão dos técnicos de contas em Portugal: do Marquês do Pombal até aos nossos dias. Jornal de Contabilidade, n. 302, p. 131-141, 2002. 
RODRIGUES, L. L.; GOMES, D.; CRAIG, R. The portuguese school of commerce, 1759-1844: a reflection of the "Enlightenment". Accounting History, v. 9, n. 3, p. 53-71, 2004.

RODRIGUES, L. L.; GOMES, D.; CRAIG, R. State intervention in commercial education: the case of the Portuguese School of Commerce, 1759. Accounting History, v. 12, n. 1, p. 55-85, 2007.

SÁ, A. L. História geral da contabilidade no Brasil. Brasília: Conselho Federal de Contabilidade, 2008.

SCHMIDT, P. Uma contribuição ao estudo da história do pensamento contábil. 1996. Tese (Doutorado em Contabilidade). Faculdade de Economia, Administração e Contabilidade, Universidade de São Paulo, São Paulo.

SEBOLD. M.; PIONER, L. M.; SCHAPPO, C.; PIONER, J. J. M. Evolução da Contabilidade brasileira: do governo eletrônico ao sistema público de escrituração digital - SPED. Enfoque: Reflexão Contábil. UEM, v. 31, n. 2, p. 23-32, 2012.

SILVA, A. C. R.; MARTINS, W. T. S. História do pensamento contábil: com ênfase na história da contabilidade brasileira. Curitiba: Juruá, 2006.

TELES, O. S. O aperfeiçoamento da contabilidade frente ao desenvolvimento da economia brasileira. Revista brasileira de Contabilidade, Brasília, n.68, 1989.

TOLEDO FILHO, J. R. A Evolução do Pensamento Contábil : crítica de alguns aspectos contábeis da legislação brasileira. 1980. Dissertação (Mestrado). Faculdade de Economia e Administração, Universidade de São Paulo, São Paulo.

TUCHMAN, G. Historical social science: methodologies, methods, and meanings. In: DENZIN, N. K.; LINCOLN, Y. S. Handbook of qualitative research. London: Sage, 1994.

VERGARA, S. C. Métodos de pesquisa em administração. 4. ed. São Paulo: Atlas, 2010.

WATANABE, I. História da Contabilidade: a profissão contábil no Brasil. Revista de Contabilidade do CRCSP, São Paulo, p.4-20, dez. 1996. 